\title{
Regímenes políticos y procesos desdemocratizadores en Nicaragua y Venezuela
}

\section{Armando Chaguaceda*}

\author{
Perfiles Latinoamericanos | Artículo \\ vol. 23 | núm. 45 | 2015 \\ pp. 5-29
}

\section{Resumen}

El texto analiza, desde una perspectiva comparada afín al enfoque de diversos autores, entre los que destaca la obra póstuma de Charles Tilly, los procesos y mecanismos específicos que explican la reciente evolución desdemocratizadora de los regímenes políticos nicaragüense y venezolano.

\begin{abstract}
From a comparative perspective similar to the focus of diverse authors - including the posthumous work of Charles Tilly-, the text analyzes the specific processes and mechanisms that explain the recent undemocratic evolution of the political regimes of Nicaragua and Venezuela.
\end{abstract}

Palabras clave: Nicaragua, Venezuela, desdemocratización, regímenes políticos, Charles Tilly. Keywords: Nicaragua, Venezuela, undemocratization, political regimes, Charles Tilly.

* Politólogo e historiador. 


\section{Presupuestos teórico-metodológicos del análisis ${ }^{1}$}

L

a politica comparada — en tanto enfoque y campo de estudio para el abordaje de los fenómenos políticos — permite profundizar el análisis empírico de contextos y procesos particulares vinculándolo con la reflexión desde la teoría política, para expresar la singularidad de cada modelo de desarrollo a partir del estudio simultáneo de las prácticas de poder y la oposición a éste (Badie, y Hermet, 1993: 7-8). Se trata de un método con fuertes anclajes en disciplinas consolidadas (politología, sociología, historia); útil para analizar fenómenos sociales de rasgos similares pero insertos en contextos distintos, identificando las semejanzas y diferencias presentes en su génesis y desarrollo. Lo que comporta los riesgos derivados del abordaje — siempre abierto a nuevas interpretaciones - de objetos de estudio complejos.

En tanto, como plantean dos reconocidos autores, "comparar no significa conocer lo complejo, elaborado y complicado de cada trayectoria política”, sino "desviarse por los caminos de los otros para demostrar que poder, legitimidad y política no quieren decir lo mismo siempre, que según los lugares pueden practicarse de diferentes maneras y que así remiten a sistemas de sentidos y a aplicaciones que pueden ser muy diversos, incluso opuestos" (Badie, y Hermet, 1993: 147), en este texto la atención se centra en el decurso de procesos de desdemocratización, que involucran estructuras institucionales y acciones ciudadanas en niveles nacionales y locales de los dominios estatal y asociativo de dos países latinoamericanos. Desde tal punto de vista, se elige una perspectiva secuencial, que establece los pasos y formas específicos de procesos a través de los cuales se van combinando variables y mecanismos ${ }^{2}$ que han sustentado el decurso desdemocratizador de los regímenes políticos de Nicaragua y Venezuela contemporáneas. ${ }^{3}$ El propósito de semejante mirada es profundizar el conocimiento

1 El autor agradece las atinadas críticas y sugerencias de los colegas Alberto J. Olvera, Luis Daniel Vázquez y Salvador Martí a las primeras versiones del presente trabajo, así como las pertinentes observaciones de los dictaminadores anónimos. Además, quiero expresar el reconocimiento de los colegas cuyas ideas nutrieron sustancialmente el diálogo y proceso investigativo que derivaron en el presente artículo: Margarita L. Maya, María P. G. Guadilla, Juan E. Romero, Angie Largaespada, Silvio Prado, Angel Saldomando, Gisela Zaremberg y Julio Aibar, entre otros.

2 El análisis comparativo de procesos como éstos supone la contrastación de secuencias evolutivas, la detección de variables causales en un número pequeño de casos (Badie, y Hermet, 1993: 55) y el establecimiento de su comparabilidad a partir de la reunión de elementos relevantes y correlacionables (Whitehead, 2011: 256-257).

3 La noción de régimen político alude al conjunto de instituciones y procesos - formales e informalesque conectan al Estado y la ciudadanía, determinan el acceso a los cargos públicos y señalan los actores, recursos y estrategias admitidos o excluidos en dicho acceso (O’ Donnell, 2010: 33). 
de ambos casos — antes que establecer supuestos patrones universales-, ubicando las singularidades y semejanzas dentro de un marco histórico, regional y nacional ${ }^{4}$ que enfatiza, en correspondencia con la investigación que dio origen al presente artículo, lo acaecido en ambas naciones hasta el año 2011. Y hacerlo dentro de una narrativa coherente que permita ubicar los acontecimientos dentro de procesos evolutivos de largo aliento y con finales abiertos, donde la historia sea "narrada" incluyendo los juicios, interpretaciones y preferencias del investigador, sin obviar por ello los matices y complejidades objetivos de los procesos concretos (Whitehead, 2011: 337).

Se exploran las trayectorias de ambos regímenes políticos comprendiendo que los avances y retrocesos democráticos no se producen en secuencias estandarizadas, sino mediante combinaciones de mecanismos específicos de democratización y/o desdemocratización (Tilly, 2010: 113). Los cuales abarcan, entre otros: a) la emergencia/repliegue de redes de confianza amplias —capaces de relacionar diversos grupos social y políticamente dominantes con sectores populares y/o excluidos del poder-; b) el fortalecimiento o eliminación de centros de poder autónomos — como la burocracia estatal y los líderes regionales—; c) la ampliación o disolución de redes clientelares - a través de la política social-, que aumentan o disminuyen desigualdades de todo signo; $d$ ) la expansión o acotamiento de mecanismos institucionalizados que requieren el concurso ciudadano — como elecciones para la aprobación y/o legitimación de las autoridades—; e) la expansión o represión de ciclos de movilización que buscan mejorar los derechos ciudadanos, $\mathrm{y} f$ ) el protagonismo o contención de fuerzas militares. ${ }^{5}$

Por su parte, en este texto se concibe la democracia como la conjunción de un ideal normativo (un modo de vida), un movimiento social (prodemocrático), un proceso socio-histórico (las diversas fases de la democratización) y un régimen político — suma de valores, prácticas y reglas institucionalizados—, que garantizan y hacen efectivos los derechos, la participación y la representación de la ciudadanía en un contexto específico. Resulta, por lo tanto, un

4 Mirada que perfecciona "[...] la precisión de análisis comparativos más amplios [...] especificando subtipos y aclarando su alcance y limitaciones; o recalibrando categorías generales de clasificación y esquemas interpretativos de acuerdo con la retroalimentación de dos casos examinados conjuntamente" (Whitehead, 2011: 279) de forma tal que al "plantear preguntas similares o buscar las analogías entre solo dos instancias de democratización" sea posible "llegar a conclusiones claras e instructivas (a generalizaciones de medio rango, en lugar de a leyes regulares generales o a estimaciones de probabilidad) que se abocan al 'espesor' o complejidad e indeterminación de los procesos individuales" (Whitehead, 2011: 289).

5 En consonancia con tal perspectiva, los gráficos incluidos en el artículo únicamente procuran visibilizar mejor las dimensiones y mecanismos que operan en cada caso —-señalando las semejanzas y diferencias entre éstos-, pero no señalar, con precisión numérica, grados específicos de desarrollo o decrecimiento de las diferentes variables que expresan los procesos de democratización/desdemocratización. 
constructo social que debe comprenderse bajo una perspectiva de largo aliento, plural y abierta a las contingencias (Whitehead, 2011: 15), la cual reúne, en sus formatos y contextos contemporáneos, tanto las conquistas y demandas orientadas a la mayor equidad y participación en los asuntos públicos, como la mejor calidad de la representación y deliberación políticas. En relación con lo anterior $-\mathrm{y}$ pese a que factores socioeconómicos (desarrollo, equidad y movilidad sociales) son elementos imprescindibles para la concreción de cualquier noción sustantiva de democracia-, en el presente texto, a partir de la estrecha relación con el marco analítico seleccionado, el foco recae específicamente sobre aquellos factores directamente relacionados con el componente político e institucional del fenómeno democrático: niveles de participación y movilización ciudadanas, presencia de actores autoritarios, redes y centros de poder, etcétera.

Al ubicar a ambos casos — aunque más nítidamente el venezolano- dentro de la corriente identificada, por un sector de la academia y opinión pública latinoamericanas, como progresismo, se alude a gobiernos que apuestan por un rescate de la capacidad y el rol estatales en la formulación de las políticas públicas; atienden de forma sustantiva las problemáticas de equidad y justicia social, a través de políticas universalistas o planes focalizados; se identifican, de forma genérica, con una ampliación de la democracia más allá de sus formatos tradicionales -insistiendo, en diverso grado, en la refundación nacional a través de nuevas o reformadas constituciones-, y se plantean un nuevo tipo de inserción internacional, menos subordinada a las agendas de los poderes globales dominantes, sean éstos potencias como Estados Unidos o empresas trasnacionales. ${ }^{6}$

No sin conflicto, estos procesos combinan un conjunto de transformaciones institucionales relevantes - el impulso a mecanismos de democracia participativa y directa, por ejemplo - con el rescate de la cuestión social y la reconfiguración y/o emergencia de identidades sociales y políticas; enfrentando obstáculos derivados, entre otros factores, de la confluencia entre las enormes expectativas de cambio radical y expedito de parte de sectores tradicionalmente excluidos de la ciudadanía, y la demanda que hacen éstos de una gestión eficaz y eficiente. Dentro de su estrategia para afrontar esas problemáticas, los gobernantes enfatizan la figura del pueblo - y su inclusión por la vía del reconocimiento simbólico y la provisión de bienes y servicios - apelando a una movilización social que desborda las instituciones representativas tradicionales y construyendo una matriz de conflicto polarizante, que tributa a la concentración de poderes en el Ejecutivo y fomenta el decisionismo autoritario.

6 Para un abordaje del fenómeno progresista, desde una perspectiva plural, véanse De la Torre, y Arnson (2013), Stefanoni (2012), Elías (2006), y Leyton, Raus, y Moreira (2008). 


\section{El peso de la historia}

La evolución de los regímenes políticos en Nicaragua y Venezuela está ligada, en cada caso, a los procesos de consolidación de una economía y un aparato estatal, desplegados desde las primeras décadas de la pasada centuria. Procesos que revelan, por un lado, modos históricos específicos de producción de lo político - como esfera de la actividad humana ligada a los asuntos del poder- y de desarrollo de la política —en tanto dimensión específicamente institucionalizada de aquella - en cada contexto — donde diversos mecanismos se alimentan en su origen de características culturales específicas (Badie, y Hermet, 1993: 65-70) ${ }^{7}$ - ; y, por el otro, el influjo ejercido sobre los procesos nacionales por la inserción en un orden económico y político internacionales. Y que, vistos en su secuencialidad, revelan cómo "[...] la configuración inicial de un poder, territorializado o no, y más o menos centralizado o penetrante, influye en la forma que adquiere después como Estado o sistema de dominio", y el modo en que tal "secuencia de la estatización determina el cuadro territorial, administrativo, humano e incluso mental de las posteriores secuencias de formación de los grupos dirigentes, así como el aumento o la limitación de la participación popular" (Badie, y Hermet, 1993: 92).

En ambos casos (como en toda Latinoamérica) se desarrollan tras la independencia "Estados periféricos", que reúnen en su seno un aparato institucional, contenidos de dominación de clase y formas específicas de control territorial. Los cuales responden simultáneamente a intereses y dinámicas externas — que favorecen relaciones de dependencia- y a actores internos preocupados en mantener la gobernabilidad. Estados que han coexistido con sociedades frágiles y dependientes, marcadas por la fuerza de poderes periféricos tradicionales y —durante mucho tiempo - por la precariedad e inestabilidad del poder central (Badie, y Hermet, 1993: 180-181).

En las primeras décadas del siglo xx, tanto en Nicaragua como en Venezuela, aparecieron regímenes de nuevo tipo, que combinaron el personalismo, ${ }^{8}$ la centralización político-administrativa y las prácticas autoritarias y clientelares,

7 Dentro del análisis comparativo, Badie y Hermet (1993: 38) destacan la necesidad de poner "[...] en perspectiva a los diferentes sentidos que dan a lo político, en el espacio y el tiempo, diferentes colectividades, y, por ende, las diferentes construcciones de lo político que de aquí se derivan”, para evitar, entre otros factores, los riesgos de considerar "[...] a priori que las mismas variables tienen la misma pertinencia y la misma categoría explicativa en las diferentes historias que se comparan” (Badie, y Hermet 1993: 56).

8 Así, según Badie y Hermet (1993: 93) "El voluntarismo y el talento de los principales responsables de los procesos de cambio, o de estabilización, proporcionan uno de los ejes para el análisis comparativo, respecto de su capacidad para actuar en un ambiente impuesto". 
estableciendo así los cimientos de una moderna estatalidad; y que abrigaron formas de modernización conservadoras (aprovechando recursos financieros y administrativos foráneos), combinadas con una estrategia de apropiación completa del poder político. Lo que supuso la eliminación o neutralización de poderes tradicionales (caudillos regionales y grupos oligárquicos) y la penetración/protección de ámbitos sociales extensos (mediante prácticas clientelares y neopatrimonialistas), para evitar la resistencia y/o emergencia de competidores políticos (Badie, y Hermet, 1993: 182). ${ }^{\text {? }}$

Sin embargo, la naturaleza de los recursos económicos y el control ejercido sobre éstos por parte del Estado, parecen marcar pautas diferenciadoras en los procesos histórico-políticos de ambas naciones. Aunque a inicios del siglo xx, el panorama de Nicaragua y Venezuela presentaba notables semejanzas (predominio del mundo rural, protagonismo de caudillos locales, economía de autoconsumo, limitada vinculación a la economía y política internacionales), a partir de la tercera década de esa centuria la diferencia entre ambas realidades nacionales fue notoria; tanto en la escala de los procesos socioeconómicos como en la naturaleza de los fenómenos políticos. Sin que ello supusiera la desaparición, en ningún caso, de elementos (militarismo, ${ }^{10}$ personalismo, desfase entre la norma y la práctica social) ligados a una añeja tradición política común, recurrente en la región.

En Nicaragua la economía agroexportadora (Kinloch, 2008) supuso la existencia de diversas élites locales, ${ }^{11}$ con las cuales el gobierno central debió negociar cuotas de poder, incluso en las etapas de mayor capacidad estatal cuando esta negociación operaba básicamente en los términos definidos por el dictador y con su hegemonía indisputada en los marcos del régimen neopatrimonialista. Una estructura social con fuerte presencia del componente campesino (proletario o propietario), con una clara rivalidad regional que trasladaba sus disputas al terreno político-partidario (con la existencia de los partidos Liberal y Conservador), y la desconexión de un amplio segmento del territorio nacional con los centros y redes de poder político y económico, fueron factores que sirvieron de contexto

9 Ante el debate sobre si las estrategias y mecanismos implementadas para construir la capacidad estatal obedecieron a lógicas acabadas o si fueron resultado de coyunturas "[...] lo más probable es que las estrategias dignas de ese nombre pueden configurarse poco a poco, en el transcurso de los períodos decisivos de profundos disturbios, mientras que la práctica golpista define la normalidad de la rutina política" (Badie, y Hermet, 1993: 93).

10 La presencia del componente militar (su lógica pretoriana y su espíritu de cuerpo) ofrecieron a los gobernantes de estas naciones importantes recursos de poder (formas de organización, orden jerárquico y medios de coerción, además de capacidad tecnológica) y dieron impulso al esfuerzo modernizador (Badie, y Hermet, 1993: 282).

11 Élites que, con frecuencia, no buscan dirigir por sí mismas el Estado, pero sí que éste les garantice el acceso a los recursos y la fuerza de trabajo, el control social y la estabilidad económicas (Tilly, 2010: 242). 
para el desarrollo de situaciones de conflicto (Esgueva, 1999) y, en correspondencia, de regímenes y culturas políticos claramente definidos por sus rasgos autoritarios (Pérez, 2008). Además, Estados Unidos operaba como un factor decisivo de poder en la política doméstica, que sólo se verá parcialmente atenuada por el régimen emanado de la Revolución de 1979.

Semejante cuadro histórico de la institucionalidad nicaragüense corresponde al patrón de un Estado débil que ha padecido numerosos obstáculos para avanzar en la democratización, en tanto fracasa en acotar la incidencia de los centros de poder autónomos (en este caso, insertos en la propia estructura estatal y la camarilla dirigente), en integrar en la política pública ${ }^{12}$ las redes de confianza existentes (de la propia oligarquía, así como de sectores medios y populares) y en reducir las desigualdades (Tilly, 2010: 206) de todo signo — socioeconómicas, étnicas, políticas, etc. - presentes en el panorama nacional. Posteriormente, aunque de forma inédita, el proceso revolucionario iniciado en 1979 expandió la capacidad estatal, inició pasos democratizadores (convocatorias a elecciones y ampliación de la participación popular) y redujo las formas más agudas de desigualdad — sobre todo en áreas de políticas sociales—, no pudo (por una mezcla de presión externa, precariedad material y errores de sus dirigentes) profundizar de forma cabal el proceso democratizador y la transformación de la cultura política tradicional (Pérez, 2008). Su saldo más visible (y positivo) fue el respeto a la fórmula electoral y la alternancia política desde las elecciones de 1990 (Kinloch, 2008).

A partir del fin del gobierno sandinista, si bien se incrementó el componente democratizador dentro de la vida política nacional — con la estabilización de un sistema de partidos, la constitución de entes reguladores en el área electoral y/o hacendaria, así como cierta expansión y pluralización de la sociedad civil (Martí, y Close, 2009)—, la capacidad estatal se vio disminuida no sólo por el enorme coste económico producido por la guerra civil, sino también por la nueva orientación neoliberal de las políticas económicas nacionales, al calor de las directrices de los organismos internacionales emanadas del Consenso de Washington. ${ }^{13}$ Por otra parte, la ampliación de las desigualdades

12 Utilizamos aquí la noción en el sentido que le otorga Tilly en su obra (2010: 44): centrada en los procesos políticos dentro y fuera del Estado donde se relacionan funcionarios y ciudadanos, excluyendo únicamente los nexos más personales, puntuales y cotidianos. Por lo tanto, el término es conceptualmente diferente al que desde el uso corriente dado en los textos de ciencia política y administración pública, identifica las agendas y acciones de gobierno orientadas a atender demandas y problemas específicos de la población.

13 Centroamérica sigue siendo una región anclada en el subdesarrollo, con enormes franjas poblacionales lastradas por la pobreza y la desigualdad, que dependen del autoempleo y su inserción en empresas basadas en la baja tecnología y la explotación intensiva de mano de obra barata, con estructuras tributarias atrasadas y sistemas de seguridad social prácticamente inexistentes. 
sociales de todo género, la reemergencia de viejas élites y posturas conservadoras —en los terrenos políticos y religiosos_-, así como la persistencia de agudos conflictos territoriales, sociales y políticos (Esgueva, 1999), impidieron la integración de redes de confianza y la reducción de los centros de poder autónomos dentro del panorama político nacional.

Gráfica 1. Regímenes políticos en Nicaragua, 1900-2011

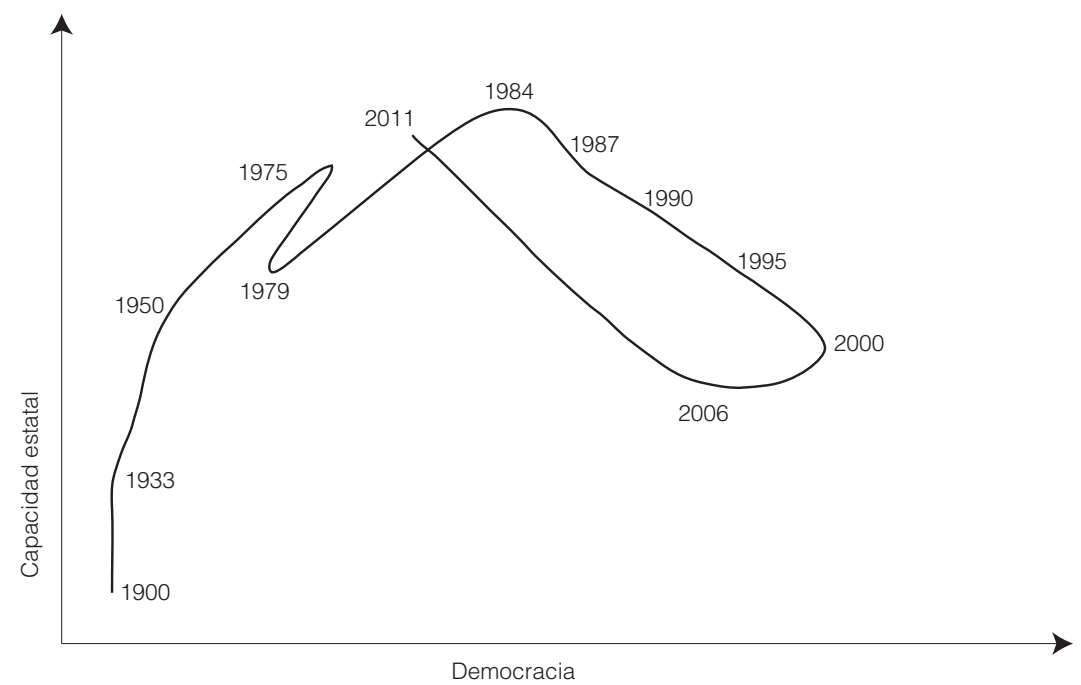

\footnotetext{
Año Comentarios

1933 Inicio de régimen somocista.

1950 Consolidación institucional del régimen somocista.

1975 Inicio de crisis final del régimen somocista.

1979 Triunfo de la Revolución.

1984 Primeras elecciones y Asamblea Nacional (parlamento) pluripartidistas.

1987 Aprobación de Constitución (hoy vigente).

1990 Triunfo de oposición antisandinista y transición democrática.

1995 Consolidación institucional de régimen democrático de transición.

$2000 \quad$ Inicio de crisis de régimen democrático de transición.

2006 Regreso al poder de Frente Sandinista: Gobierno de Reconciliación y Unidad Nacional.

2011 Reelección de Ortega, conflictos políticos y crisis institucionales.
}

Fuente: Elaboración propia a partir de bibliografía sobre el país (véanse las referencias al final del texto). 
Por su parte, la experiencia venezolana muestra, a pesar de la persistencia de elementos comunes con la nicaragüense - factor militar, autoritarismo, debilidad de la ciudadanía—, el creciente peso que el control estatal sobre los ingresos provenientes del petróleo (Caballero, 2009) y la paulatina aparición de un vasto aparato y burocracias impulsoras del culto bolivariano y el paternalismo estatal (Carreras, 1984) tuvieron en la configuración, durante el siglo xx, de regímenes no democráticos de alta capacidad (Tilly, 2010: 208). De tal suerte, el caso venezolano parece confirmar la hipótesis de Tilly, relativa a que "[...] en los Estados que prosperan gracias a sus monopolios sobre recursos comercializables, como el petróleo, los gobernantes defienden sus monopolios por medio del empleo de una parte significativa de sus ingresos en reproducir las separaciones entre los miembros de sus propias instituciones para el mantenimiento de obligaciones y todas las demás", formando parte de un universo de experiencias nacionales que "abarcan muy variadas ideologías pero que emplean abundantes ingresos procedentes del petróleo en construir redes de apoyo a los gobernantes y de exclusión de su oposición" (2010: 154). ${ }^{14}$

Esta evolución tuvo una peculiar trayectoria histórica y antecedentes políticos. A lo largo del siglo xIx, diferentes gobiernos autoritarios promovieron en Venezuela formas de participación relativamente iguales y amplias (movilizativas, con una ciudadanía armada y caudillos dirigentes); acompañadas de un acendrado personalismo político y profundas carencias (Carreras, 1984) en lo relativo a la necesaria protección y consulta vinculante que, desde la perspectiva de Tilly, ligan Estado y ciudadanía bajo estándares democráticos. Para inicios del xx, el venezolano era un Estado débil tomado por militares (Caballero, 2009), con una ciudadanía de baja intensidad y un régimen no democrático de poca capacidad. ${ }^{15} \mathrm{La}$ situación comienza a cambiar de forma rápida con la producción petrolera, a fines de la década de 1920. Desde entonces — y hasta nuestros días - se incrementará espectacularmente la capacidad estatal, fenómeno acompañado a partir de 1935 y hasta 1958 por una modesta (e intermitente y temporalmente revertida) ${ }^{16}$ trayectoria de modernización (Caballero, 2009) y democratización (Tilly, 2010: 213-216). Con lo cual parece demostrarse la tesis que postula que en trayectorias de Estado fuerte la capacidad estatal suele

14 Así “Tanto en las economías capitalistas como en las no capitalistas, la dependencia de estos recursos genera amplias desigualdades de categoría entre aquellos que los controlan y aquellos que o bien carecen de acceso a ellos o bien están bajo su influencia." (Tilly, 2010: 154).

15 Para la correlación entre capacidad estatal y calidad de la democracia véase Tilly (2010: 47-56).

16 En Venezuela "[...] la ausencia de antecedentes útiles parece haber contribuido a un camino errático, en el cual no estaba garantizada la transición inicial a la democracia, y se requería una década más de política coercitiva antes que las élites relevantes encontraran una forma para diseñar reglas mutuamente tranquilizadoras del juego democrático" (Whitehead, 2011: 307). 
crecer antes de que exista una democratización significativa. Y que aun cuando el fortalecimiento del Estado puede activar procesos de subordinación de las élites a la política pública, de eliminación de las desigualdades y crecimiento de poder popular, esa capacidad también puede servir para bloquear — en algún momento de la trayectoria - el propio proceso democratizador (Tilly, 2010: 203-204).

Con la expansión de la renta petrolera (en las décadas de los setenta y los primeros ochenta) aumentó la integración parcial de redes de confianza — procedentes de clases medias y trabajadores sindicalizados (Gómez, 2009)—, misma que se erosionó debido a la crisis combinada del sistema político populista de conciliación de élites y del modelo económico rentista a fines de la etapa. ${ }^{17}$ Durante la década de 1990, la confluencia de esta crisis, el auge de la antipolítica y el cuestionamiento a la función de los partidos, llevaron a sectores de la población a apostar a un outsider que refundara el orden sociopolítico vigente.

Para el arribo de Hugo Chávez se produjo un proceso de integración más o menos amplia de una sociedad civil afín (Gómez, 2009) con instancias de participación y redes de confianza procedentes de sectores populares y/o marginados (Tilly, 2010: 214). Al tiempo que se avanzó a un régimen de alta capacidad no democrático, de tempranos rasgos personalistas y autoritarios (Arenas, y Gómez, 2006). Bajo un gobierno que alega (y apela) constantemente a una legitimidad "revolucionaria" y al uso sistemático "[...] de un recurso privilegiado de poder que ya no es equilibrado por la intervención de otros recursos" (Badie, y Hermet, 1993: 194-195), tanto por el control del aparato burocrático, el ejercicio del poder carismático del líder o por su empleo de recursos económicos estatales y la captura de aquellos pertenecientes a la empresa privada nacional y extranjera.

En medio de escenarios de conflictividad y polarización políticas, aunados a magros desempeńos estatales (a pesar de la inédita expansión de su capacidad) en el área de políticas públicas, Venezuela enfrenta un proceso desdemocratizador, cuyos efectos se han acumulado durante años (Arenas, y Gómez, 2006). Aparece el recurso del factor militar como estrategia autoritaria frente a los progresos de la oposición y, en un sentido amplio, a los propios efectos sociales de un populismo (Badie, y Hermet, 1993: 281) que inicialmente expande cierto empoderamiento local y genera inclusión social de sectores populares; a

17 Tilly plantea que en la Venezuela de fines del siglo xx concurrieron dos factores que tributan a los procesos desdemocratizadores en regímenes con Estados fuertes y relativamente democráticos, siendo éstos "[...] la deserción del pacto democrático de actores políticos de élite que previamente lo habían aceptado, y las crisis económicas tan agudas que agotan la capacidad del Estado para mantenerse a sí mismo y cumplir sus compromisos" (Tilly, 2010: 218). De hecho, el autor plantea que en la historia del país los “[...] múltiples períodos de desdemocratización combinaron de forma característica la crisis económica con la deserción de las élites de los consensos parcialmente democráticos” (Tilly, 2010: 218). 
lo que habrá que añadir el efecto en estos sectores beneficiados de las promesas incumplidas en diversos rubros. También existe la posibilidad — cercana tras los inéditos avances de la oposición - de desplazamientos potencialmente democratizadores en Venezuela, en el sentido de que "la represión gubernamental podría unir a la oposición, en lugar de fragmentarla en rivales que reclaman para sí el control del Estado" (Tilly, 2010: 247).

Gráfica 2. Regímenes políticos en Venezuela 1900-2011

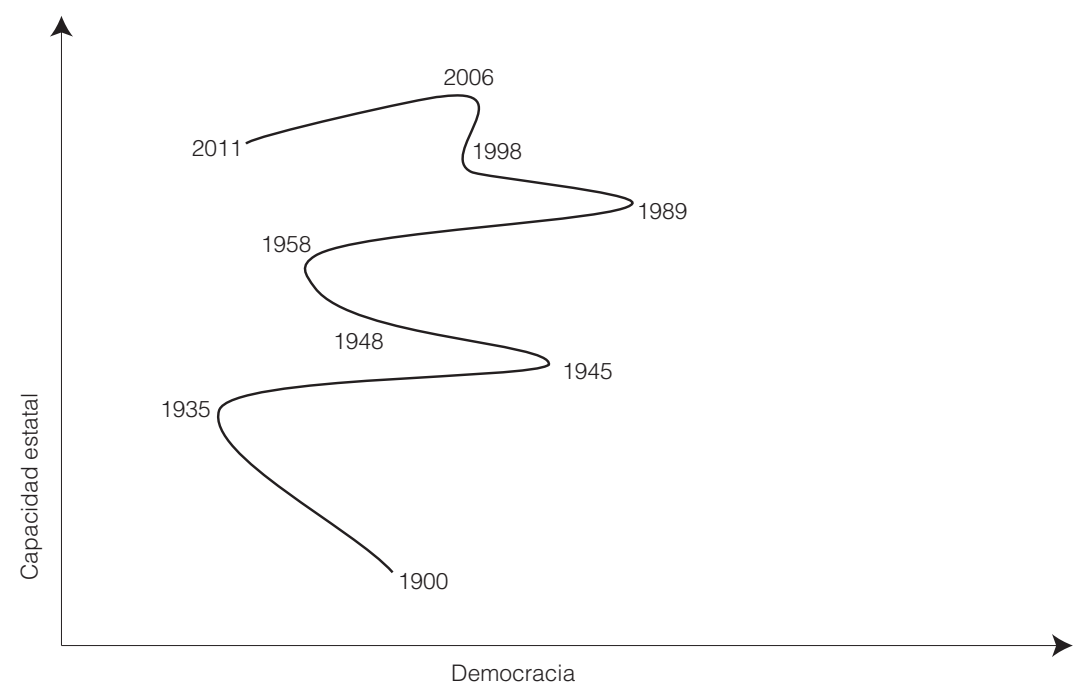

\footnotetext{
Año Comentarios

1900 Inicio del régimen de Juan Vicente Gómez: personalismo, modernizador y auge petrolero.

1935 Muerte de Juan Vicente Gómez, inicio de la transición a la democracia.

1945 Golpe civil-militar y gobierno democrático: fortalecimiento de capacidades y rol estatal.

1948 Golpe militar, dictadura de Marcos Pérez Jiménez: interrupción temporal de la transición.

1958 Caída de la dictadura, inicio del régimen puntofijista y fase democrática de la IV República: democracia bipartidista y presidencialista.

1989 Crisis del puntofijismo y la IV República: el Caracazo como protesta sociopolítica contra políticas de ajuste.

1998 Ascenso de Hugo Chávez y proyecto bolivariano: inclusión social y polarización política.

2006 Segunda fase chavista: polarización sostenida y giro autoritario (socialismo del siglo XXI).

2011 Conflictos de polarización, crisis del chavismo, ascenso electoral de la oposición.
}

Fuente: Elaboración propia a partir de bibliografía sobre el país (véanse las referencias al final del texto). 


\section{La mecánica del cambio}

Una mirada comparada resulta insostenible si sólo narra, con grandes trazos, procesos históricos que marcan la evolución de regímenes políticos específicos. Si queremos explorar dentro de las trayectorias particulares de los regímenes cuáles son los elementos que afectan las posibilidades de democratización y desdemocratización, tenemos que recordar que éstas dependen de los cambios en tres dimensiones de análisis (la integración de redes de confianza, los niveles de desigualdad existentes, y la incidencia de centros de poder autónomos) seleccionadas por Tilly (2010) dentro de su modelo analítico, tomando en cuenta las interacciones que se producen entre diversos mecanismos. Entre éstos se encuentran la existencia de redes que relacionan, de forma plural, segmentos de las élites y de los excluidos, u otras que ligan actores pertenecientes a los grupos social y políticamente dominantes respecto de sectores populares y/o excluidos del poder; el fortalecimiento o eliminación de centros de poder autónomos (burocracia estatal y líderes regionales); la ampliación o disolución de redes clientelares a través de la política social, lo que incide en el aumento o disminución de las desigualdades; la expansión o disminución de actividades que requieren el concurso ciudadano (elecciones para la aprobación y/o legitimación de las autoridades); la expansión o represión de ciclos de movilización que mejoren derechos ciudadanos, y el protagonismo o contención de fuerzas militares. De forma tal que los avances y retrocesos democráticos no se producen en secuencias estandarizadas, sino en combinaciones de mecanismos específicos dentro de estas dimensiones, para facilitar o dificultar el sometimiento estatal a la política pública y la influencia popular sobre ésta (Tilly, 2010: 113).

En ambos países, las redes de confianza han sufrido el impacto de los procesos desdemocratizadores. En Nicaragua se ha reforzado el papel de movimientos religiosos y organizaciones productivas/territoriales (cooperativas) vinculadas a iniciativas del gobierno, mientras que la situación de confrontación ha obligado a las organizaciones de la sociedad civil autónoma a defenderse del acoso gubernamental, reduciendo los recursos recibidos por una cooperación internacional en retirada. La Iglesia católica y las asociaciones empresariales mantienen (y en algunos casos amplían) su incidencia social, mientras que una buena parte del movimiento popular entrega su trabajosamente ganada autonomía —y la autogestión que a ésta se liga — al ser subsumido en las redes clientelares del partido gobernante. Redes que se amplían de forma selectiva para incluir a aquellos actores considerados relevantes — procedentes de sectores populares y/o medios- que estén dispuestos a sacrificar su autonomía por recursos y protección oficial. Como se aprecia, la extendida pobreza, el reducido tamaño del territorio nacional y la relativa simplicidad de la estructura social nicaragüense 
— con una poco desarrollada clase media — facilitan que el oficialismo implemente su labor de cooptación y control de las redes tradicionales y bloquee la emergencia de otras alternativas que disputen (a nivel simbólico o efectivo) su poder e influencia sociales, así como el lugar de los grupos dominantes dentro de la sociedad y política locales.

El caso venezolano difiere cualitativamente del nicaragüense, a partir de la mayor complejidad y equidad sociales, la extensión territorial y la correlación de fuerza de actores en pugna. Aunque la labor de expansión de redes de confianza vinculadas a la política y organización sociales promovidas por el gobierno —al amparo de la renta petrolera - ha sido apreciable en barrios populares y zonas urbanas, en el país existen regiones (entre ellas estados de peso económico como el Zulia y fronterizos como el Táchira) donde las redes de confianza relacionadas con actores de clase media, religiosos $\mathrm{u}$ organizaciones civiles mantienen una vitalidad apreciable, que los vincula al trabajo de los partidos y liderazgos de la oposición, así como a amplios sectores populares. Además, el creciente descontento de estos últimos con los resultados de las políticas sociales del gobierno (en términos de sostenibilidad, cobertura y calidad) hace que la labor de cooptación y control de las estructuras políticas del Partido Socialista Unido de Venezuela — cuya solidez y operatividad más allá de las directrices y apoyos oficiales son permanentemente cuestionados - no sea decisiva. Si bien han aparecido actores colectivos directamente vinculados al proceso (organizaciones populares y sectoriales bolivarianas), se constata un creciente protagonismo de actores (estudiantiles, comunitarios, civiles) ajenos al oficialismo o que asumen una posición abiertamente opositora, lo cual complejiza el campo político a partir de su incidencia relevante en dominios estatales y societales y en las arenas participativas y autonómicas.

En lo relativo a los comicios, en los dos países se han realizado de 2006 a la fecha diversos procesos para la elección de las autoridades regionales, nacionales y parlamentarias, cuyos resultados han sido analizados detalladamente en diversas investigaciones y artículos de expertos de ambas naciones. Si bien en ambos casos nacionales el oficialismo ha dispuesto de ventajas en cuanto al empleo de recursos públicos y los tiempos de emisión de propaganda en medios masivos, ${ }^{18}$ entre uno y otro existen diferencias apreciables.

En Nicaragua, la directa cooptación y sujeción del poder electoral, así como de buena parte del sistema judicial por parte del Frente Sandinista de Liberación

18 Cabe recordar que este tipo de elecciones semicompetitivas — que constituye una categoría amplia de experiencias históricas - se ven mediatizadas por factores que abarcan desde la imposición de restricciones al número y tipo de partidos concurrentes y el veto a partidos pequeńos, hasta el establecimiento de un partido hegemónico o frente oficial (Badie, y Hermet, 1993: 249) que controla asimétrica y abrumadoramente el acceso a los recursos y medios de propaganda de casa al proceso electoral. 
Nacional (FSLN), y la renuencia a implementar formas de veeduría ciudadana y observación foránea, unidas al empleo de la intimidación (y en algunos casos de la represión) a ciudadanos que intentaban fiscalizar el proceso electoral o protestar por lo que consideraban manifestaciones de fraude, son signos reveladores de la precariedad de este mecanismo democrático. Sumado a ello, el impacto que tienen las prácticas clientelares en la intención de voto de amplios sectores populares —urbanos y rurales_-, permite explicar el estado de la cuestión en la nación centroamericana.

En el caso venezolano es destacable la existencia de un ente regulador (el Consejo Nacional Electoral) cuyo desempeño ha sido relativamente profesional, ${ }^{19}$ así como la amplia fiscalización electoral opositora (y en general ciudadana) y la observación internacional, que se han constituido en garantes de la democracia. Ello, unido a la rearticulación y renovación parcial de las estructuras y liderazgos opositores dentro de la Mesa de la Unidad Democrática, han permitido un paulatino y sostenido avance en las preferencias electorales, que se vio reflejado en la victoria obtenida en varias entidades territoriales clave (Lara, Miranda) en comicios regionales, así como en la composición del nuevo Parlamento electo en 2010, donde la oposición recuperó una presencia significativa, perdida tras su fatal decisión de no concurrir a los comicios legislativos de 2005.

Otro elemento para comparar, es el estado de los ciclos de movilización social —que apuntan a la mejora de derechos ciudadanos-, donde se generan prácticas de autonomía relevantes; y las políticas de participación mediante las cuales los ciudadanos pretenden incidir en el desarrollo de las políticas y agendas de gobierno, sobre todo a nivel local. Si bien en ambos casos se aprecia la expansión de modelos de participación partidizados y vinculados al poder estatal —unida a formas de criminalización de la protesta social— los informes de entidades especializadas de ambos países dan cuenta de importantes diferencias cualitativas. ${ }^{20}$

En la historia política de Nicaragua, la tardía construcción de una estatalidad moderna y el marco autoritario en que se implementó — de forma visible en la época somocista y ambigua en la revolucionaria- conllevaron a que hasta inicios de la década de 1990 no asistiéramos a la coexistencia de políticas de participación debidamente normadas e institucionalizadas, y una sociedad civil emergente que reivindicase la autonomía como valor esencial de su identidad y accionar, para diferenciarse de los actores paraestatales de regímenes anteriores. Emanados de la lucha contra los gobiernos y políticas neoliberales de fines

19 En sus decisiones, aunque en su composición el oficialismo cuenta con una apreciable ventaja de 4 a 1.

20 Véanse al respecto las investigaciones desarrolladas por organizaciones civiles como cinco (Nicaragua) y provea (Venezuela), así como los trabajos de Silvio Prado, Angie Largaespada, Roberto Stuart y Angel Saldomando, entre otros expertos. 
del siglo xx, hoy existe en Nicaragua un conjunto de actores organizados de la sociedad civil autónoma — como el movimiento de mujeres, organizaciones juveniles y de derechos humanos—, que enfrentan de forma más o menos activa lo que consideran un avance autoritario del gobierno nacional. Sin embargo, ese accionar no es acompańado por una buena parte de sectores y organizaciones populares, que se encuentran cooptados por políticas del FSLN.

Gráfica 3. Relación entre políticas de participación y políticas de autonomía en Nicaragua, 1900-2011

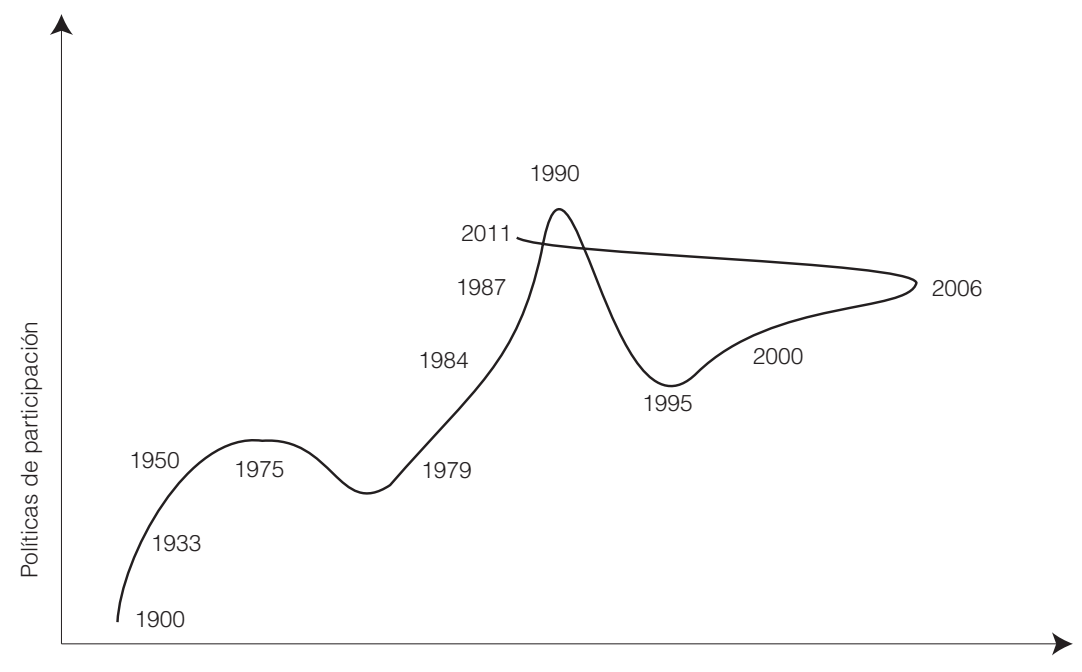

Prácticas de autonomía

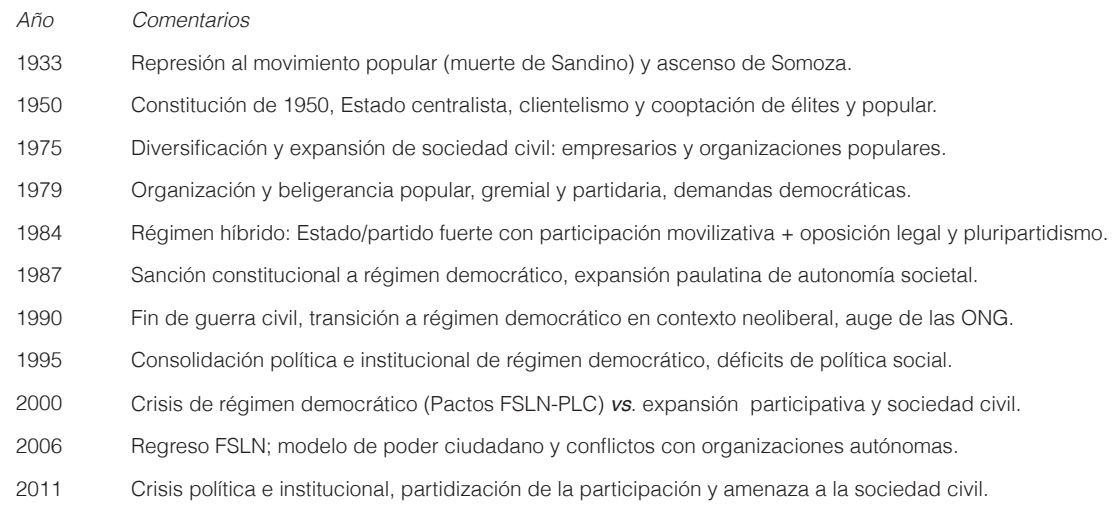

Fuente: Elaboración propia a partir de bibliografía sobre el país (véanse las referencias al final del texto). 
Gráfica 4. Relación entre políticas de participación y políticas de autonomía en Venezuela, 1900-2011

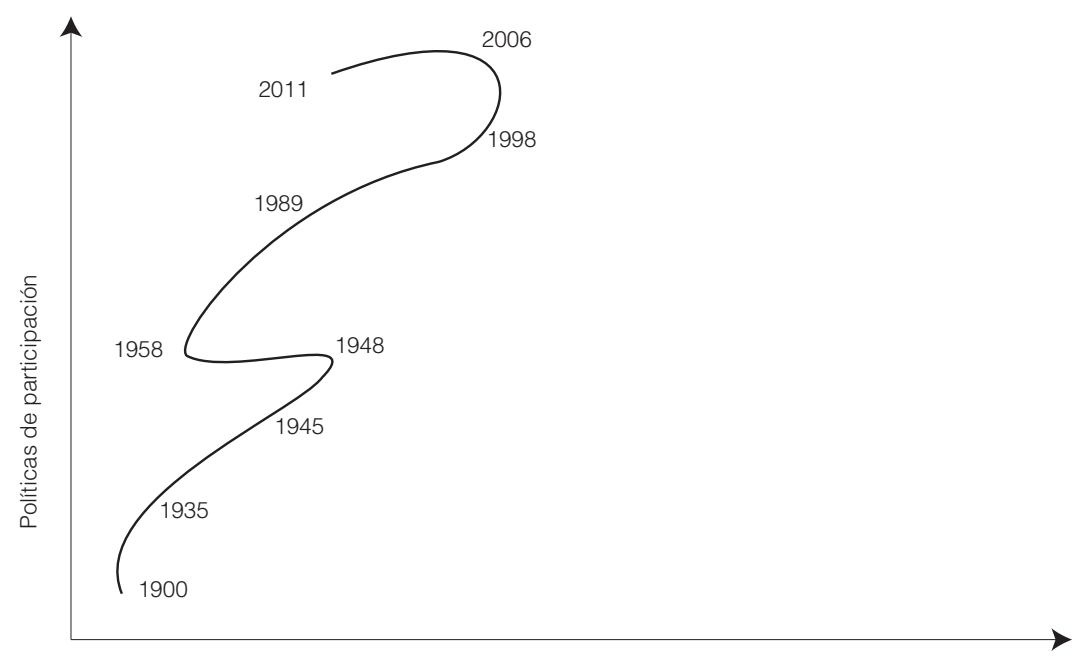

Prácticas de autonomía

$\begin{array}{ll}\text { Año } & \text { Comentarios } \\ 1900 & \text { Consolidación centralista, clientelismo, subordinación de los poderes locales y societales. } \\ 1935 & \text { Emergencia de acción ciudadana (gremios, estudiantes), aparición de partidos, demandas democráticas. } \\ 1645 & \text { Constitución democrática, derechos sociales y políticos, consolidación de partidos. } \\ 1948 & \text { Retroceso autoritario, represión de sociedad civil y partidos, beligerancia popular. } \\ 1958 & \text { Triunfo cívico-militar, inicio de la democracia, predominio bipartidista y cooptación societal. } \\ 1989 & \text { Crisis de la democracia, crecimiento de organización y protesta popular y de clase media. } \\ 1998 & \text { Fin del bipartidismo, ascenso de la nueva hegemonía y proyectos políticos en pugna, expansión partici- } \\ 2006 & \text { pativa y polarización social. } \\ & \text { Giro del proyecto chavista: impulso a participación estatizada y control de autonomía societal, creci- } \\ 2011 & \text { Recuperación sociopolítica y electoral de oposición, endurecimiento de posturas oficialistas, incertidum- } \\ & \text { bre por enfermedad de Chávez. }\end{array}$

Fuente: Elaboración propia a partir de bibliografía sobre el país (véanse las referencias al final del texto).

Asimismo, las estructuras de participación reconocidas por la ley (como los Consejos de Desarrollo Municipal) han visto casi desaparecer su presencia por el protagonismo de los Gabinetes y Consejos de Poder Ciudadano, ligados éstos a la capacidad de redistribuir recursos procedentes del aparato estatal y la cooperación venezolana, lo cual ha generado dinámicas predominantes 
de cooptación y exclusión, así como conflictos con organizaciones y comunidades opositoras (Chaguaceda, y Stuart, 2011). Después de las elecciones generales de noviembre de 2011, el oficialismo alcanzó una mayoría dentro del Parlamento que, sumada al control del aparato estatal central, de buena parte de gobiernos locales y a la presencia de su "tendido organizacional" partidario y social en todo el territorio nacional, configura escenarios de conflicto para la acción de aquel sector de la ciudadanía no identificado con la orientación de su proyecto político y la consolidación de un régimen de rasgos acusadamente neopatrimonialistas.

En Venezuela, si bien el desarrollo de políticas de participación (López, 2011) y la emergencia de una ciudadanía beligerante a través de la sociedad civil (Gómez, 2009) son fenómenos relativamente recientes (de 1958 en adelante), el periodo de gobierno chavista, en especial los últimos años, ha sido el escenario de una aguda disputa por la inserción ciudadana en los procesos participativos $\mathrm{y}$ de enfrentamiento a las pretensiones autoritarias y estatizantes del gobierno.

La expansión de un modelo de participación (Poder Comunal) — que busca subsumir la institucionalidad en el ámbito local y dispone de importantes recursos para ello- no ha cristalizado por un conjunto de factores que van desde la complejidad de la estructura social y territorial venezolanas, la dinámica imprimida por los frecuentes cambios institucionales y diversos conflictos políticos, así como por la resistencia ciudadana — de adversarios y simpatizantes del chavismo - a aquellos elementos del Poder Comunal que perciben como nocivos, tanto por su magro desempeño en el área de las políticas públicas como por el sesgo excluyente y polarizador que han mostrado al utilizárseles desde el oficialismo (López, 2011). A ello se une la expansión de una acción societal que, enarbolando el amplio catálogo de derechos consagrados en la Constitución de la República Bolivariana de Venezuela (CRBV), hace uso de diversos mecanismos de protesta y denuncia ciudadana, para confrontar tanto los déficits de los servicios públicos como los retrocesos y agresiones contra los derechos civiles y políticos de la población.

Otro factor clave para comprender el alcance de los procesos desdemocratizadores lo constituye el rol que juegan los militares dentro del orden social y su incidencia en la limitación de los derechos ciudadanos. La experiencia previa de regímenes autoritarios en la historia nicaragüense y venezolana revela un papel destacado de los elementos castrenses como impulsores de los procesos de modernización y desarrollo de la capacidad estatal, agentes represores de las diversas formas de disidencia y oposición antigubernamentales. No será hasta el advenimiento del régimen puntofijista (1958) y durante la etapa de transición en Nicaragua (a partir de 1990) cuando la sujeción del mando militar al poder civil, así como la mayor incidencia de la sociedad civil, van a configurar escenarios en los cuales la 
ciudadanía organizada podrá influir en la política pública sin que los conflictos político-institucionales corran, salvo excepciones, el riesgo de degenerar en confrontaciones armadas entre sectores de la sociedad, y de éstas con el aparato estatal y la institución armada. ${ }^{21}$

En los últimos años, en ambos países el proceso de implicación de los militares en la política ha sido variable. En Nicaragua, el gobierno mantiene relativamente fuera del juego al ejército y la policía - los cuales se profesionalizaron y redujeron sus efectivos-, contentándose con garantizar la impunidad de sus adherentes cuando, por ejemplo, se trata de reprimir marchas opositoras con la recurrente pasividad de agentes policíacos. No obstante la movilización de tropas en el conflicto con Costa Rica por el río San Juan y el apoyo del presidente Ortega a la permanencia en el cargo de la jefa de la Policía, Aminta Granera -institución cuya profesionalidad ha sido reconocida por la opinión pública-, parecen sugerir un interés en acercar/cooptar a los cuerpos armados y a los de interior. El esquema de poder construido por el orteguismo (mezcla de poder estatal/partidario, control de instituciones y organizaciones sociales afines, y alianza con sectores económicos y países extranjeros donantes) hasta el momento parece prescindir del factor militar como variable relevante en su ecuación. Asistimos a un caso donde la desdemocratización no ha ido de la mano de un mayor protagonismo del elemento castrense, toda vez que el resto de los recursos en manos del Estado y la debilidad de sus oponentes y de la sociedad civil tornan innecesario el uso de la fuerza armada y policíaca como mecanismo de proyección del poder.

En Venezuela, el factor militar fue esencial desde los orígenes del actual proceso, tanto por la procedencia del máximo líder, por el antecedente expresado en los dos golpes militares de 1992 (matrices del movimiento bolivariano y su iconografía), como por su imbricación con elementos civiles — pertenecientes al universo partidista y societal de la izquierda venezolana- para configurar la alianza cívico-militar que accedió al poder por vía electoral en 1998. Desde los primeros años del gobierno chavista, los militares — quienes recuperaron el derecho al voto con la CRBV — tuvieron protagonismo — aprovechando sus recursos

21 Esta situación debe ser presentada con dos importantes matices. En el caso venezolano, la institución armada confrontó movimientos guerrilleros y populares durante la década de 1960, cuya represión implicó afectaciones a los derechos humanos de segmentos de la población, además de que para finales de los ochenta y principios de la década siguiente la represión del Caracazo y los alzamientos militares de 1992 pusieron en duda la solidez del proceso de despolitización y profesionalización del cuerpo armado. Por su parte, en Nicaragua, si bien el ambiente de guerra civil y las restricciones emanadas del diseño del régimen revolucionario (con fusión de partido, Estado y fuerzas sandinistas, incluidos los cuerpos armados y de seguridad) limitaron la expresión plural, pacífica y protegida de la ciudadanía, esa institucionalidad castrense fue factor clave para el respeto al proceso electoral que llevó a la derrota del gobierno sandinista, así como a la implementación relativamente pacífica del proceso de transición. 
y capacidad organizativa - en la implementación de diversos planes sociales, labores de vigilancia comicial y reconstrucción ante desastres naturales. Tras el golpe de estado de abril de 2002, la presencia de jefes militares en instituciones clave (en la administración y la estratégica producción petrolera) y en las candidaturas oficialistas a los gobiernos de disputadas regiones opositoras (o en el comando de autoridades paralelas, creadas por el presidente para disputar los gobiernos regionales y locales opositores) se incrementaron de forma exponencial, casi al unísono de la expansión del gasto militar (mejoras salariales, compra de armamento a Rusia, activación de nuevas unidades) y la mayor presencia de lo militar (marchas, celebraciones, desfiles, lenguaje) dentro del activismo y discursos chavistas.

Sin embargo, pese a la rotación de comandos (jubilación de oficiales poco confiables y ascenso de otros vinculados al presidente), la penetración del adoctrinamiento político y el control de inteligencia dentro de los cuerpos armados, la situación no parece haber sido del todo favorable al control del elemento castrense por el gobierno. Una fuerza militar, de tamaño y complejidad relativamente importantes, opera como un mecanismo de poder que acompaña al presidente en tanto sus decisiones no pongan en riesgo la estabilidad del país y la cohesión del instituto armado. Además, la vitalidad y capacidad de innovación de la oposición y sociedad civil venezolanas supera con creces la de sus homólogas nicaragüenses, dando al factor civil mayores oportunidades en la posible reversión de los cursos desdemocratizadores. Los escenarios actuales presagian que el factor militar será decisivo — pero no único— en la configuración del orden político poschavista.

\section{Un balance final: cruzando los casos y sus enseñanzas}

En los últimos años, la experiencia de los gobiernos llamados progresistas ha evidenciado — a la par de una apuesta por la inclusión social— procesos de clara concentración de poder en el Ejecutivo, de implementación de formatos participativos carentes de autonomía y colonizados por el Estado (a su vez controlado por el partido oficial), y de penalización o acoso a organizaciones e iniciativas de la sociedad civil. Todo ello apunta a la conformación de nuevos campos de lucha, simbólica y material, en torno a la participación y acción colectiva, donde los actores impulsarán sus respectivas agendas de cambio político.

A partir de este precedente, es posible presentar una relación de los mecanismos y procesos que caracterizan la actual deriva desdemocratizadora en Nicaragua y Venezuela, en el periodo 2006-2011. En el primer caso es notable la existencia 
de una aguda polarización de actores y conflictos (como los relacionados con las elecciones de 2008 y 2011), que se une a la reforzada incidencia de redes tradicionales (como las iglesias católica y protestantes) a partir de su vínculo con las agendas gubernamentales; y la coexistencia de niveles aceptables de participación electoral y de un modelo oficialmente promovido, partidizado y excluyente, de participación en los ámbitos locales a partir de la implementación de las estructuras (Gabinetes y Consejos) del denominado "Poder Ciudadano". A la vez, el acceso ampliado — pero desigual y selectivo- de la población a recursos, a través de diversos programas desarrollados por el gobierno nacional (por ejemplo: Hambre Cero, Usura Cero) mediante la canalización selectiva de la abundante ayuda venezolana, apunta a la consolidación de estrategias (por regiones y grupos poblacionales considerados relevantes) de clientelismo y a la utilización de elementos formalmente ciudadanizadores (por ejemplo, la cedulación electoral) como mecanismos para el control/movilización políticos por parte del partido gobernante.

La autonomía del grupo dirigente — que ha purgado de su seno aquellas figuras y/o grupos que potencialmente pudieran amenazar el dominio de Ortega y su esposa - y la fusión en su seno de intereses estatales y privados, los beneficios concedidos a aliados (empresariales, eclesiales), la capacidad de control de los poderes públicos (electoral, justicia) y el éxito en la confrontación con los partidos opositores y la sociedad civil, revelan un incremento (relativo) de la capacidad estatal y una menor influencia ciudadana (sobre todo aquella que se canaliza de forma institucionalizada) dentro de la política pública. Así, las relaciones entre el Estado y la ciudadanía van adquiriendo — y consolidando - en Nicaragua, ciertas características que las hacen tendencialmente asimétricas, desprotegidas y no vinculantes, tributando a la paulatina desdemocratización del régimen político y orden social del país centroamericano.

En cuanto al caso venezolano, si bien persiste - y a ratos se agudiza - la polarización sociopolítica, ésta se ha expresado de forma privilegiada a través de mecanismos institucionales; en especial en procesos electorales, donde la participación ha sido, como promedio, alta en los diferentes estratos poblacionales. Durante los últimos ańos, a la existencia de segmentos de voto "duro", afectos al oficialismo y la oposición, se han añadido nuevas redes y actores (populares, estudiantiles, ambientalistas, liderazgos y grupos emergentes de la oposición) que compensan la expansión de un modelo de participación ciudadana partidizada y excluyente como el llamado "Poder Comunal". Algunas de estas redes pueden tener su sustrato en elementos no explícitamente político-partidarios (grupos de clase media, regionalismos, juveniles, etc.), pero se activan e inciden en su entorno inmediato y a nivel nacional en coyunturas políticamente relevantes, como las electorales. 


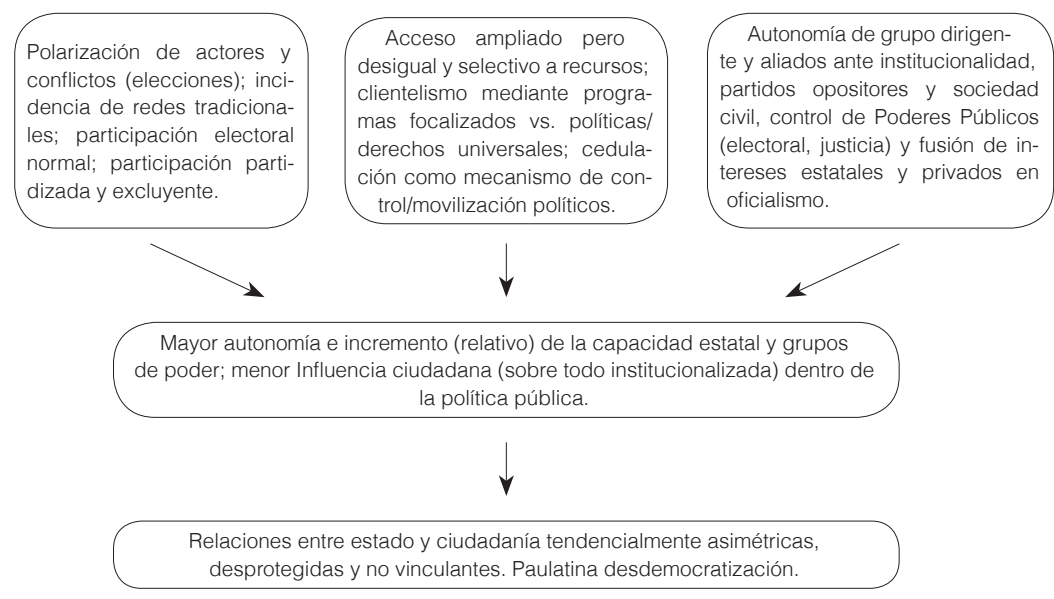

Fuente: Elaboración propia a partir de Tilly (2010: 179).

La ampliación de programas y políticas sociales — con sus déficits de calidad, sostenibilidad e impacto—, si bien ha sido utilizada por el gobierno nacional (y por gobiernos regionales opositores) para fines proselitistas, también ha expandido el estatuto de ciudadanía de sectores excluidos y los ha dotado de derechos que pueden esgrimir frente a los funcionarios públicos. Ello explica la expansión de la protesta y acción colectivas - oficialista y opositora- en los últimos ańos, pese a los esfuerzos por criminalizarla. Sin embargo, eso no ha sido impedimento para la extensión del poderío de diversos centros de poder autónomos (Ejecutivo, Fuerza Armada, líderes regionales), cuya capacidad ha crecido frente al resto de la institucionalidad, los partidos opositores y la sociedad civil, lo que se une al control oficialista de algunos poderes públicos (justicia) y el crecimiento a su amparo de un sector empresarial identificado como "boliburgués".

Como saldo, coexisten una amplia capacidad y autonomía estatales encaradas por una variable influencia ciudadana dentro de la política pública. Ello configura relaciones entre Estado y ciudadanía tendencialmente asimétricas, poco protegidas y moderadamente vinculantes, donde la predisposición desdemocratizadora en curso encuentra expresiones de resistencia (y potencial reversión) por parte de la ciudadanía. 


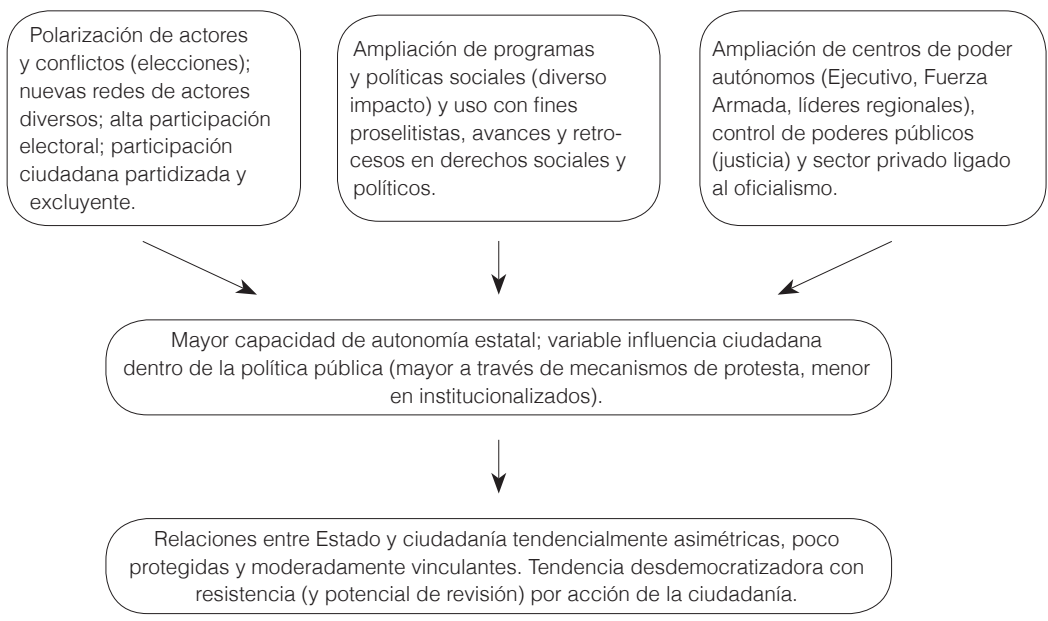

Fuente: Elaboración propia a partir de Tilly (2010: 179).

En ambos casos las coordenadas institucionales, legales y los mecanismos específicos de interacción Estado-ciudadanía se ven afectados por relaciones caracterizadas por la asimetría, la conflictividad y la contingencia, entre representantes del Estado y ciudadanos organizados, que parecieran favorecer la imposición de regímenes claramente autoritarios y no simples expresiones de la democracia delegativa identificada por Guillermo O’Donnell años atrás. En ambos casos, resalta la tardía integración de las economías y sociedades nacionales a las dinámicas del capitalismo global, la persistente dependencia económica de la producción de productos primarios (agrícolas en Nicaragua, hidrocarburos en Venezuela) a lo largo de las dos pasadas centurias, así como la vulnerabilidad de modelos productivos y estructuras políticas altamente dependientes de los mercados, inversiones e injerencia política de las potencias foráneas. Y resultan visibles los procesos de construcción de las capacidades estatales, conducidos bajo regímenes autoritarios durante la primera mitad del siglo xx. Al tiempo que se revela la diferenciación en los cursos de evolución política respectivos: la consolidación en Nicaragua de un régimen sultánico de carácter familiar (la dinastía de los Somoza), y la prolongada transición a un régimen democrático — controlado por los partidos — en el caso venezolano. 
Desde esos marcos se explica la debilidad de la capacidad estatal y la precariedad del orden democrático en el caso nicaragüense, que son correlativos a la persistencia de una estructura social conservadora y profundamente desigual, una lenta evolución histórica y la constante sujeción de las dinámicas de su política interna a la injerencia estadounidense. Y se llama la atención sobre los efectos que el factor petróleo (y su derivación cultural, el rentismo) ha tenido en la economía y política venezolanas, caracterizadas por esfuerzos modernizadores conducidos por medio del protagonismo del Estado y de los partidos políticos.

A partir del análisis de los procesos antes descritos, es posible sostener que asistimos a la consolidación — precaria y nunca irreversible- de nuevas formas de dominación que incorporan de forma subordinada y distorsionada las lógicas y demandas (redistributivas, ciudadanizantes) de movimientos sociales originariamente identificados con un rescate de la justicia social, del rol regulador y activo del Estado y de la expansión e innovación democráticas. Sin embargo, los liderazgos nacionales de ambos países han procurado afianzar el poder del Estado y construir regímenes políticos caracterizados, cada vez más, por sus rasgos estatistas, autoritarios y personalistas. Incluso han construido alianzas entre ambos gobiernos —intercambiando recursos, asesoría e información-y con potencias extracontinentales afines, como Rusia, China e Irán (Vanderhill, 2012). Y en tanto resulta precario contraponer la defensa de la inclusión social y el respeto al ejercicio integral de los derechos políticos de mayorías y minorías, lo que bajo estos regímenes se construye no es otra cosa que una hegemonía estatal no equiparable sino más bien, enajenantea cualquier visión de hegemonía socialista o progresista, pensada en clave del pensamiento de E. Laclau, Ch. Mouffe o de otros autores afines a la idea de una profundización — republicana, posliberal— de la democracia.

Todo ello permite concluir enfatizando que, en los últimos ańos, a pesar del desarrollo de amplias políticas sociales y de la retórica progresista al uso, tanto en Nicaragua como en Venezuela se ha ido consolidando un tipo de relación conflictiva entre las políticas de participación — generadas desde la estatalidad-y las prácticas de autonomía societales que presagian escenarios mucho más hostiles para quienes propugnen una mayor democratización de la vida política y constituyen caldo de cultivo para el estallido de situaciones de conflicto que ponen en riesgo la convivencia al interior de esas sociedades. Convivencia que debería hallar formas virtuosas — pacíficas, democráticas, ciudadanizantes - de concreción, de modo que el gobierno de los hombres y la administración de las cosas dejen de ser patrimonio exclusivo de nuevos Leviatanes; aun de aquellos que dicen gobernar(nos) en el nombre del pueblo. 


\section{Bibliografía}

Arenas, Nelly, y Luis Gómez, 2006, Populismo autoritario: Venezuela 1999-2005, Caracas, CENDEs/Universidad Central de Venezuela.

Badie, Bertrand, y Guy Hermet, 1993, Politica comparada, México, FCE.

Caballero, Manuel, 2009, La crisis de la Venezuela contemporánea (1903-1992), Caracas, Alfadil Ediciones.

De la Torre, Carlos, y Cynthia J. Arnson, 2013, Latin American Populism in the Twenty-First Century, Washington D.C., Woodrow Wilson Center/Johns Hopkins University Press.

Carreras, German, 1984, Una nación llamada Venezuela. Proceso socio histórico de Venezuela (1810-1974), Caracas, Monte Avila Editores.

Chaguaceda, Armando, y Roberto Stuart, 2011, “¿Democracia participativa en Nicaragua? Los Consejos de Poder Ciudadano y el gobierno del fsln (2006-2011)”, Revista Centroamericana de Ciencias Sociales, vol. 2, núm. VIII, San José, pp. 5-22.

Constitución de la República Bolivariana de Venezuela, 30-12-1999, Gaceta Oficial No. 36860.

Elías, Antonio (comp.), 2006, Los gobiernos progresistas en debate. Argentina, Brasil, Chile, Venezuela y Uruguay, Montevideo, ClaCso/Instituto Cuesta Duarte.

Esgueva, Antonio, 1999, "Conflictos y paz en la historia de Nicaragua”, Serie Taller de Historia, núm. 7, Managua.

Gómez-Calcaño, Luis, 2009, La disolución de las fronteras: sociedad civil, representación y política en Venezuela, Caracas, cendes/Universidad Central de Venezuela.

Kinloch, Francis, 2008, Historia de Nicaragua, Managua, Instituto de Historia de Nicaragua y Centroamérica.

Leyton, J. C., D. Raus, y C. Moreira (coords.), 2008, La nueva política en América latina. Rupturas y continuidades, Montevideo, Flacso Uruguay/Universidad Nacional de Lanús/Universidad Arcis/Ediciones Trilce.

López Maya, Margarita, 2011, Democracia participativa en Venezuela (1999-2010): orígenes, leyes, percepciones y desafios, Caracas, Fundación Centro Gumilla/Universidad Católica Andrés Bello (Temas de Formación Sociopolítica). 
Martí, Salvador, y David Close (eds.), 2009, Nicaragua y el FSLN (1979-2009). ¿Qué queda de la revolución?, Barcelona, Edicions Bellaterra.

O’Donnell, Guillermo, 2010, Democracia, agencia y estado. Teoría con intención comparativa, Buenos Aires, Prometeo Libros.

Pérez, Andrés, 2008, Entre el estado Conquistador y el estado Nación. Providencialismo, pensamiento político y estructuras de poder en el desarrollo histórico de Nicaragua, Managua, Instituto de Historia de Nicaragua y Centroamérica.

Reynoso, Diego, 2008, "La brecha entre mayorías institucionales y preferencias ciudadanas en los gobiernos post-Consenso de Washington”, en J. C. Leyton, D. Raus, y C. Moreira (coords.), La nueva politica en América Latina. Rupturas y continuidades, Montevideo, Flacso Uruguay/Universidad Nacional de Lanús/Universidad Arcis/Ediciones Trilce, pp. 23-48.

Stefanoni, Pablo, 2012, "Posneoliberalismo cuesta arriba. Los modelos de Venezuela, Bolivia y Ecuador en debate”, Nueva Sociedad, núm. 239, Buenos Aires, pp. 51-64.

Tilly, Charles, 2010, Democracia, Madrid, Akal.

Vanderhill, Rachel, 2013, Promoting Authoritarianism Abroad, Boulder, Lynne Rienner Publishers Inc.

Whitehead, Laurence, 2011, Democratización. Teoría y experiencia, México, FCE.

Recibido el 19 de abril de 2013.

Aceptado el 5 de mayo de 2014. 
